\title{
POWER MANAGEMENT BY USING MULTIPORT DC - DC CONVERTER FOR RENEWABLE ENERGY
}

\author{
C Priyatharshini ${ }^{1}$, P Kathiravan ${ }^{2}$, C Govindaraju ${ }^{3}$ \\ ${ }^{I}$ M.E Student, Department of EEE, Sri lakshmi ammaal engineering college, Chennai 126 \\ ${ }^{2}$ Assistant Professor, Department of EEE, Sri lakshmi ammaal engineering college, Chennai 126 \\ ${ }^{3}$ Assistant Professor, Department of EEE, Government college of engineering, Salem 011
}

\begin{abstract}
This paper proposes, power management of different types of renewable energy source is controlled by multiport DC-DC converter. In this each port of the converter is connected with controller switch to control the source input of converter. This is reduces the turn off switching losses by soft switching. The high frequency switches are used to control the power flow. This converter is proposed to control the hybrid energy generating system, with the ability of bidirectional power flow between battery and load. The diode bridge rectifier is applicable for high switching frequency operation with realizable component compare with existing converter. The efficiency of the converter is verified through MATLAB simulation. The operation and design performance is explained briefly. The proposed converter has reliability operate simultaneous power generation from different renewable energy source. Fuzzy controller controls the direction of power flow and load voltage of the converter.
\end{abstract}

Keywords: Isolator, high frequency link, soft switching, multiport converter, PV panel, wind turbine generator (WTG). $* * *$

\section{INTRODUCTION}

Today's world has the interest to developing hybrid energy generation system, from different kind of renewable energy source. The hybrid energy generation system consist of some main issues are stability, reliability, and power quality. To use these problems storage element is used. The clean power generation world prefer PV panel and wind generation system. Multiport dc-dc converters have been proposed to do the efficient power management and load integration for the multiple sources. The isolated dc-dc converter has connected with different sources are photovoltaic (PV) panel, wind turbine generator (WTG) and battery.

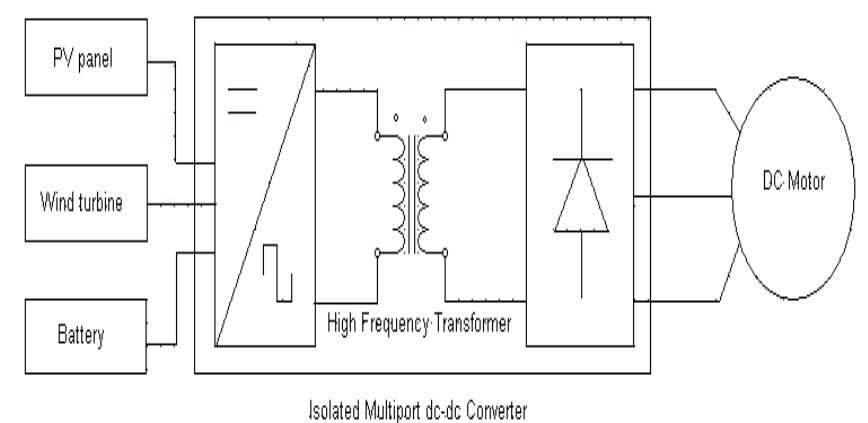

Fig.1 Configuration of single stage multiport dc-dc converter

The multiport dc-dc converter with energy storage has become a promising option for many instead of power systems, which including fuel cell vehicle, hybrid vehicle, renewable energy application and so on. It not only reduces the cost and improves the efficiency of the system performance. With its ability to reverse the direction of current flow and power. The multiport dc-dc converters are used to achieve the power transfer between sources and load. It is also regulated by the solar panel photovoltaic(PV) level and wind turbine generator(WTG) wind level, thus to maintain a stable load voltage and make fully usage of the solar panel and wind turbine generator and the storage element battery.

This converter is applicable to provide constant high level DC voltage and obtain other important function. Isolated multi port converter is mainly classified into two categories. One is separate winding method and other one is common winding method. In this common winding method consist of common ground for multi input source. This topology is proposed in power management system. Almost commonly isolated half bridge converters are used. The each side of the transformer connected with bridge type switches. The converter has multiple ports connected to a single winding on the primary side of a transformer. It is suitable for the advantage of using less number of windings in the transformer. In secondary side of the isolator consist of diode bridge rectifier. Controllable switches are used by $2 \mathrm{~m}+2$, where $m$ denotes the number of input ports. In this proposed converter switches are reduced into $\mathrm{m}+1$. This multiport dcdc converter is consists of a PV, WTG, battery and load.

Power may be controlled simultaneously use of fuzzy control to extract the maximum power from wind and sunlight respectively, by using the proposed convert. This proposed converter has only one switch is connected for each input source. In the secondary side of the converter have no controlled switches. The efficiency of the converter is increased by switch ON or switch OFF time interval, depend upon decrease peak current. 
This paper is organized as following. Introduction in section I, Construction and Operation of the converter is discussed in the section II and is analyzed modes of operation Section III. Section IV Design Consideration of converter and its control analysis in Section V. Section VI Simulation and Result and in Section VII summarized Conclusion.

\section{CONVERTER STRUCTURE}

AND

\section{OPERATION}

The proposed multi-port dc-dc converter is shown below figure 2, which is consist of high frequency transformer, that is made up of ferric core material. In the primary winding of the transformer is connected with energy storage capacitor C, and switches MOSFET1, MOSFET2, MOSFET3, MOSFET4 respectively. Full bridge diode rectifier is connected in the secondary winding of the transformer. In the secondary side LC filter is placed to reduce harmonics. Fig. 2 circuit diagram of the proposed converter is shown below. The primary side consists of three ports in parallel, each one of the port is connected with PV panel, Wind and battery. In the primary side of a capacitor $C$ is connected in between the ports and transformer. Each port contains an inductor, a power diode and a controllable power switch.

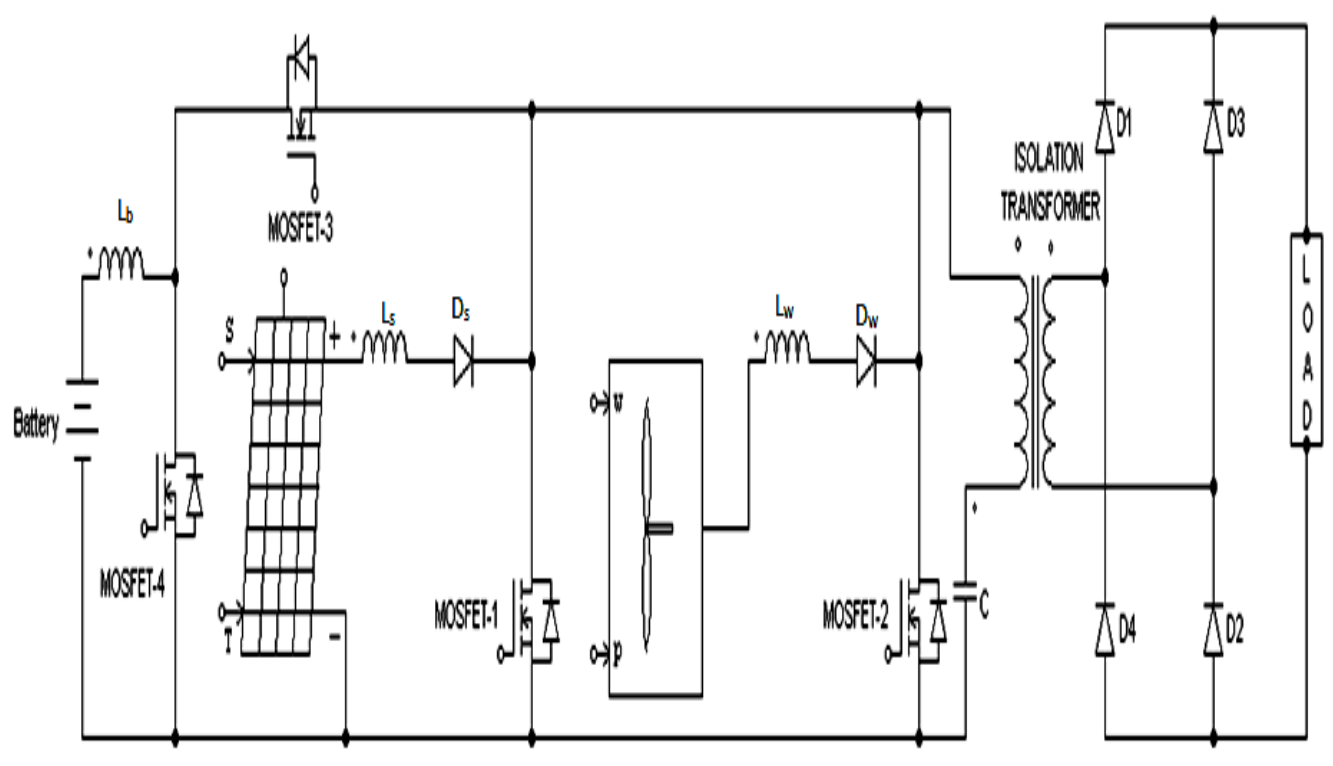

Fig.2.Circuit Diagram of MPC

The transformer's turns ratio(n) is $n=N p / N s$, where $N p$ is the number of turns of the primary winding and $N s$ is the number of turns of the secondary winding. The converter is controlled by the operation of power switches. In this proposed converter capacitors are placed in between the ports to minimize the DC voltage ripples. Motor load is connected for this converter.

\section{MODES OF OPERATION}

This converter section has three operating modes: 1) MOSFET switch $1 \& 2$ on; 2) MOSFET switch 3 is on and MOSFET switch $1 \& 2$ is off; 3 ) MOSFET switch $3 \& 4$ is on. The circuit operation during the high period of the high frequency of square wave applied to the MOSFET to turn $\mathrm{ON}$. Inductor $\mathrm{L}$ is placed between the positive and negative supply to the terminal. Therefore the current flows between the positive and negative supply terminals through the inductor L, which is stores the energy in its magnetic field. There is no current flowing in the remaining circuit as the combination of $\mathrm{D}, \mathrm{C}$ and the load represent a much higher impedance than the path directly through the heavily conducting MOSFET.
The current path during the low period of the switching square cycle wave. MOSFET is rapidly turned of sudden drop in current causes in L, to produce the back emf in the opposite polarity to the voltage across the inductor during on period, to keep current flowing.

Each time MOSFET conducts, the of D is more positive than its anode because of the charge on capacitor. When diode is turned off means, the output of the circuit is isolated from the input, the load is continues to be supplied with $V_{I N}+V_{L}$ from the charge on capacitor.

Charging and Discharging of capacitor depends on the following equations at initial condition

$$
I c=C \frac{d V c}{d t}
$$

When switch is closed $\mathrm{V}_{\mathrm{C}}$ remains constant voltage, capacitor cannot change the voltage.

$$
V c(t=0)=V c I
$$


The current flow through the capacitor, it will energize to increase voltage.

$$
V c(t>0)=V c I \quad \text { (increasing) }
$$

When the capacitor voltage increases, capacitor current will decreases.

$$
I c(t)=\frac{V s-V c(t)}{d t}
$$

\section{Mode: I}

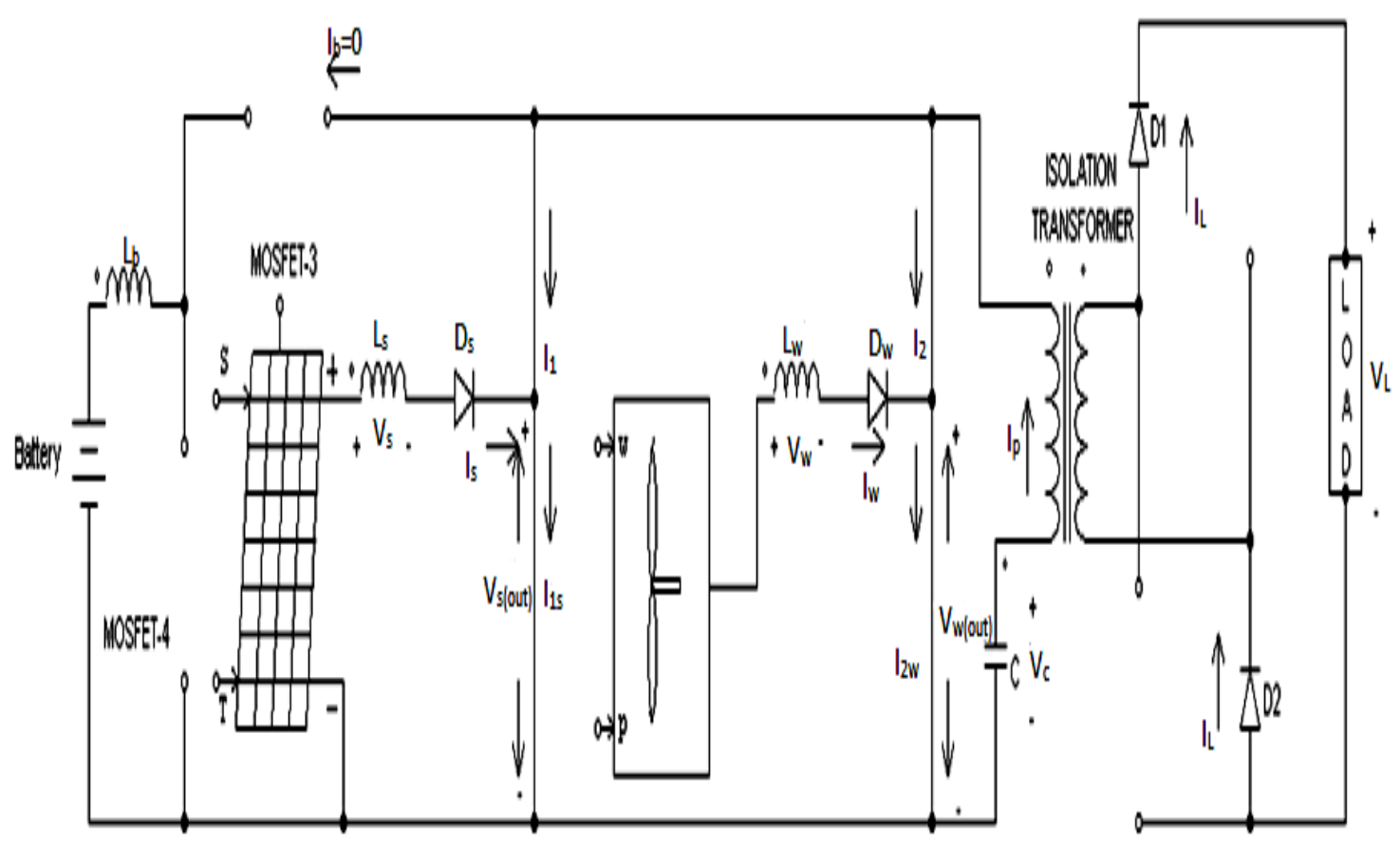

Fig.3.Circuit Diagram for Mode 1

When PV is supplying power to the load, the current path will flow in positive direction. Inductor $L_{\mathrm{S}}$ is used for boost operation and diode is used to block the voltage. MOSFET switch 1 is on condition, the capacitor will charging condition. The capacitor will charge when MOSFET1 turned $\mathrm{ON}$ in OFF condition capacitor will discharge the power to load through the high frequency transformer, D1 and D2 will conduct. Excess amount of energy is stored in battery through MOSFET3 is in ON condition, at the time battery current $\mathrm{I}_{\mathrm{B}}=0$.

$$
\begin{aligned}
& I p=I 1+I 2 \\
& I 1 s=I 1+I s \\
& I 2 w=I 2+I w
\end{aligned}
$$

$I p, I s, I w$ are primary current of the transformer, solar current and wind current respectively. $V s, V w$ are solar and wind voltage respectively. Vs out and $V w$ out is zero.

$$
\begin{aligned}
& V s=l s \frac{d i s}{d t} \\
& V w=l w \frac{d i w}{d t}
\end{aligned}
$$




\section{Mode: II}

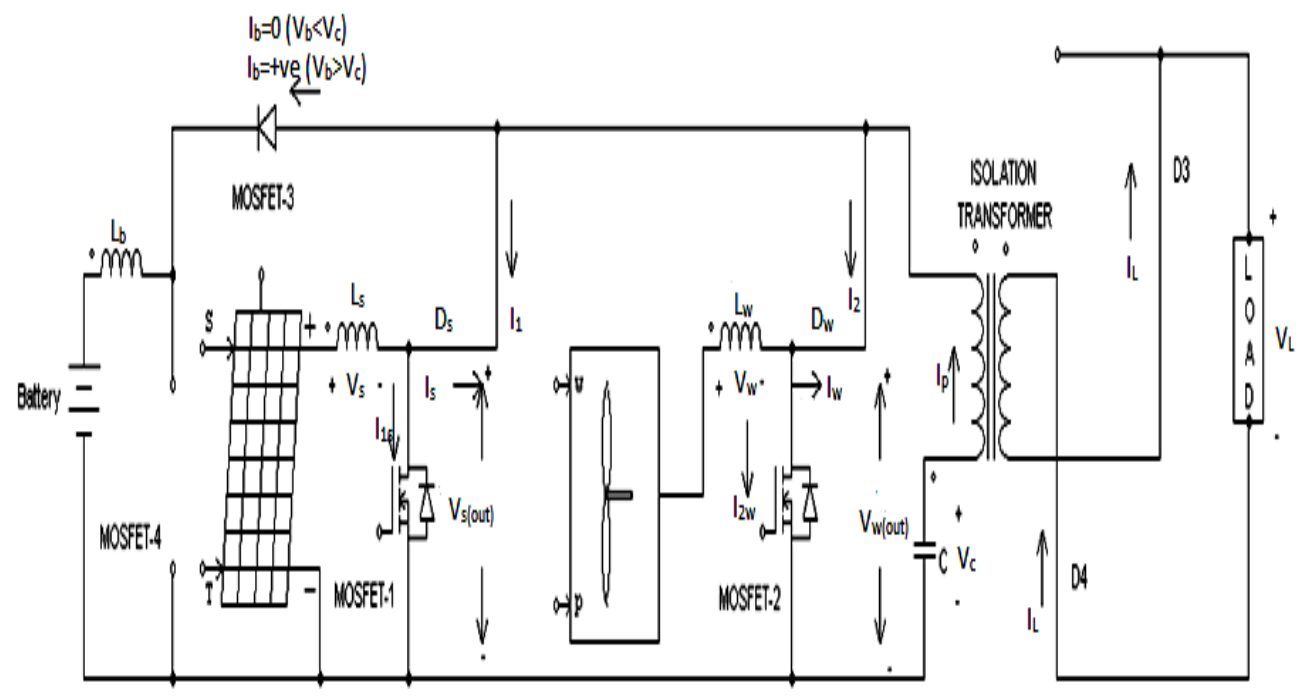

Fig.4.Circuit Diagram for mode 2

When the MOSFET1 and MOSFET2 is OFF condition the power flows through the diode. The current flows through the primary winding of the transformer to the secondary winding of the transformer for step up the voltage and Diode D1 \& D2 will conduct. when MOSFET switch 3 is on the power fed to the battery for charging and load voltage and current is $\mathrm{V}_{\mathrm{L}}$ and $\mathrm{I}_{\mathrm{L}}$. Battery for charging through bidirectional power flow only to the battery.

$$
I p=I 1+I 2
$$

$I 1$ and $I 2$ both are having opposite polarity.

\section{Mode: III}

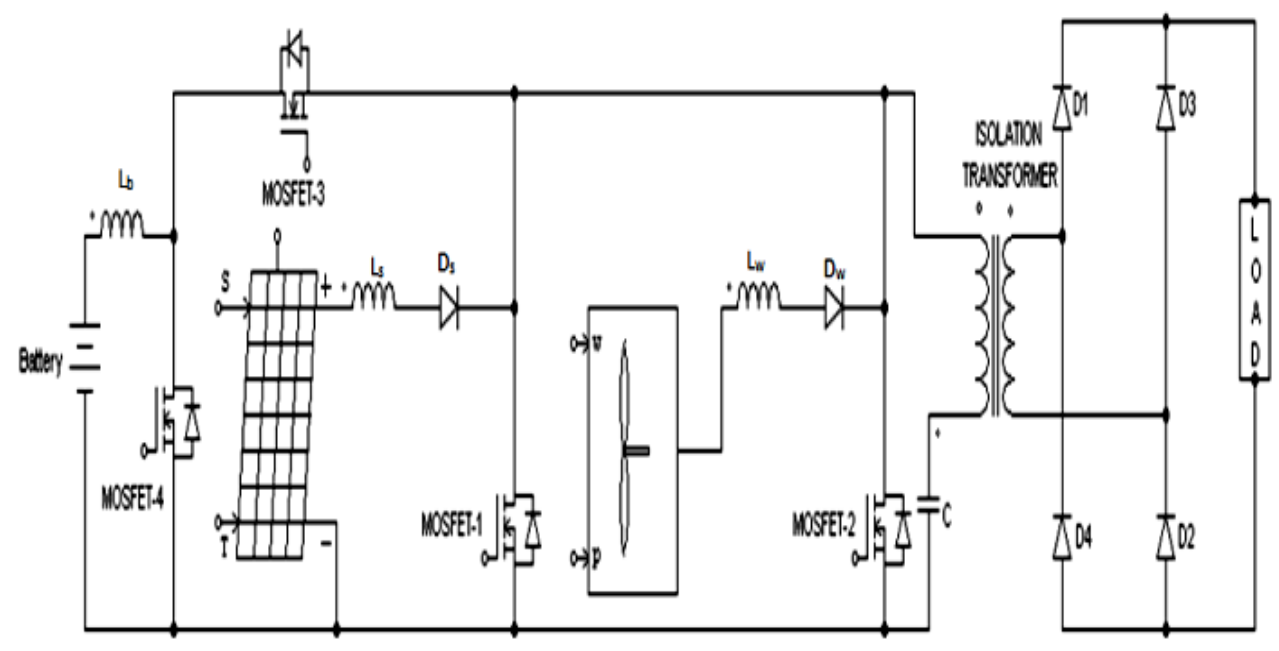

Fig.5.Circuit Diagram for mode 3 
When the MOSFET switch 4 is on condition the capacitor will charged simultaneously the MOSFET switch 3 is on condition battery will charged at the time PV and Wind generating voltage is absence condition. MOSFET 4 is off condition capacitor discharges the voltage to the primary of the transformer and the secondary winding of the transformer increase the voltage to the load. Simultaneous power flows to the load through high frequency transformer.

In battery discharging mode primary current of the transformer is

$$
I p=I 1+I 2+I b
$$

Solar and Wind voltages are similar as the mode 2 operation and then capacitor voltage is increased to

$$
V c=\frac{1}{c} \int c(t) d t
$$

\section{DESIGN CONSIDERATIONS}

The multiport dc-dc converter has a single stage conversion process with multiple ports. It is emerging because to make, the whole system more compact and simpler. This multiport dc-dc converter cannot only interface all sources and load and also modify the electrical energy form, but it regulate the power flow between the source and load. The high frequency transformer consists of ferric core, which is provide the isolation and voltage matching between source and load. The transformer turns ratio is select by using this formula

$$
\frac{N p}{V 1}=\frac{N s}{V 2}=\cdots=\frac{N n}{V n}
$$

where $N p, N s$ are transformer primary and secondary winding turns number and $V 1, V 2$ voltage of the ports. The power throughout the transformer should be maximum of all possible conditions. When switching frequency is fixed, the power flow is related to the leakage inductance and the power flow is given by

$$
P=\frac{N p V s V w}{2 \pi N s F s L s}
$$

where $\mathrm{L}_{\mathrm{S}}$ is the total inductance to the primary of transformer and $F_{S}$ is the switching frequency.

The requirements of operation on the region for the multiport dc-dc converter are the following:

1) Independently supply the load power from each of the sources;

2) Share the power between source and load;

3) When the load is regenerative, the power us used to charge the battery;

When the power flow from the port 1 to port 3, the converter operate in boost mode to keep the port 3 at a maximum desired value. The other direction of power flow, the converter operate in buck mode to charge the storage element battery.
Table .1 Multiport dc-dc converter parameter

\begin{tabular}{|l|l|}
\hline converter parameter & value \\
\hline port 1 voltage & $12 \mathrm{~V}$ \\
\hline port 2 voltage & $12 \mathrm{~V}$ \\
\hline $\begin{array}{l}\text { battery (lead acid) } \\
\text { voltage }\end{array}$ & $12 \mathrm{~V}$ \\
\hline resonant inductor & $100 \mathrm{mh}$ \\
\hline resonant capacitor & $100 \mu \mathrm{f}$ \\
\hline transformer turns ratio & $1: 2$ \\
\hline capacitor & $100 \mu \mathrm{f}$ \\
\hline duty cycle & 0.5 \\
\hline
\end{tabular}

The following requirement should be satisfied, To make multiple sources work effectively: the switch $\mathrm{S}_{\mathrm{K}}(\mathrm{K}=1,2,3,4)$ should not be turned off before $S 1$ is switched off; otherwise, $L_{\mathrm{S}}$ will continuously store energy through even $S 1$ and $\mathrm{S} 2$ is off, which is not desired. To meet this requirement, the following inequality should be satisfied for the multiport dc-dc converter, where $V_{L}$ is the output voltage of the load. The renewable energy source with the largest nominal output voltage will be connected to converter port which is may lead to one of the following two scenarios.

Scenario 1: If no power is available from Port 1, which is no longer valid but should still be satisfied. In this scenario, the duty cycle of the switch $S 1$ is set to be a constant value such that is satisfied and the function of the switch $S 1$ is to change the direction of the current $I_{P}$ flowing through the transformer. Specifically, when $S 1$ is off, the current $\mathrm{I}_{\mathrm{P}}$ flows from the other sources to the transformer to charge the capacitor $C s$. When $S 1$ is on, the capacitor $C s$ discharges so that the direction of the current $\mathrm{I}_{\mathrm{P}}$ reverses.

Scenario 2: The renewable energy source generate the power at Port 1 is low such that cannot be satisfied, should still be satisfied. In the duty cycle of the switch $S 1$ will be increased to a maximum value by the fuzzy controller such that is satisfied and the function of the switch $S 1$ is the same as that in Scenario 1. The power generated by the renewable energy source connected to Port 1 might be less than the maximum power that can be generated by the source. In this scenario, at port 1 the difference between the generated and the maximum power is small because of the maximum available power at Port1 of multiport dc-dc converter is usually very low.

\section{CONTROL ANALYSIS}

In this proposed converter is controlled by the fuzzy controller. Switches and the modes of operation of the converter is controlled by the fuzzy control. It control according to the output converter. For this, rules created depending up on the operation. Because fuzzy is a rule based system. By the membership function rules are created. The triangular curve is used as a subset. This triangular curve denotes the vector function, $\mathrm{x}$ and scalar parameters $l, h \& v$. With this formula for the membership function is 


$$
\operatorname{triangle}(x, l, h, v)=\left\{\begin{array}{cc}
0 & x \leq l \\
\frac{x-l}{h-l} & l \leq x \leq h \\
\frac{v-x}{v-h} & h \leq x \leq v \\
0 & v \leq x
\end{array}\right.
$$

This formula is simply formed as

$$
\text { triangle }(x, l, h, v)=\max \left(\min \left(\frac{x-l}{h-l}, \frac{v-x}{v-h}\right), 0\right)
$$

Where this triangle curve consist of three parameters there are $l$ is lower limit, $h$ is upper limit and $v$ is value of the function.

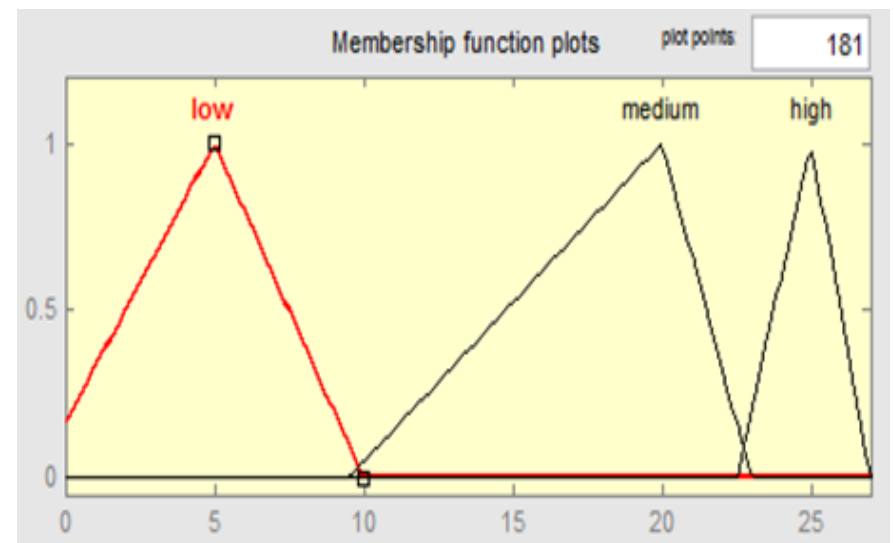

Fig.6.a. Membership Function for input

Fuzzy logic has been used for tracking the Maximum power point of PV system and wind because it has the advantages of robust, relatively simple to design and does not require the knowledge of an exact model. The fuzzy inference of the Fuzzy Logic Control is based on the Mamdani's method which is associated with the max-min composition.

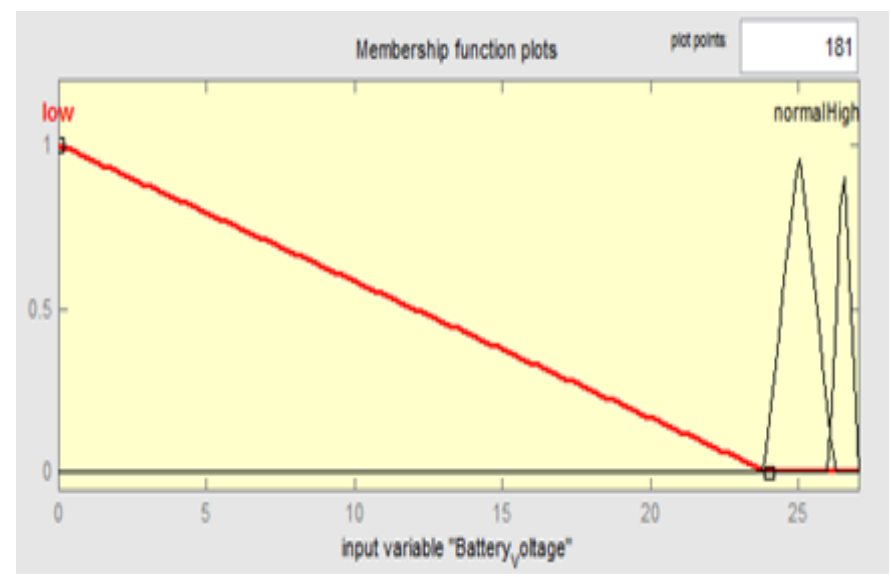

Fig.6.b.Membership Function for battery input

\subsection{Rule Viewer For Fuzzy Control}

The below fig.7(a) shows the set of rules in fuzzy control. The linguistic values to numeric values changed by using centre of the gravity defuzzification method. Hence, the MPPT using fuzzy logic can improve the performance of the system.

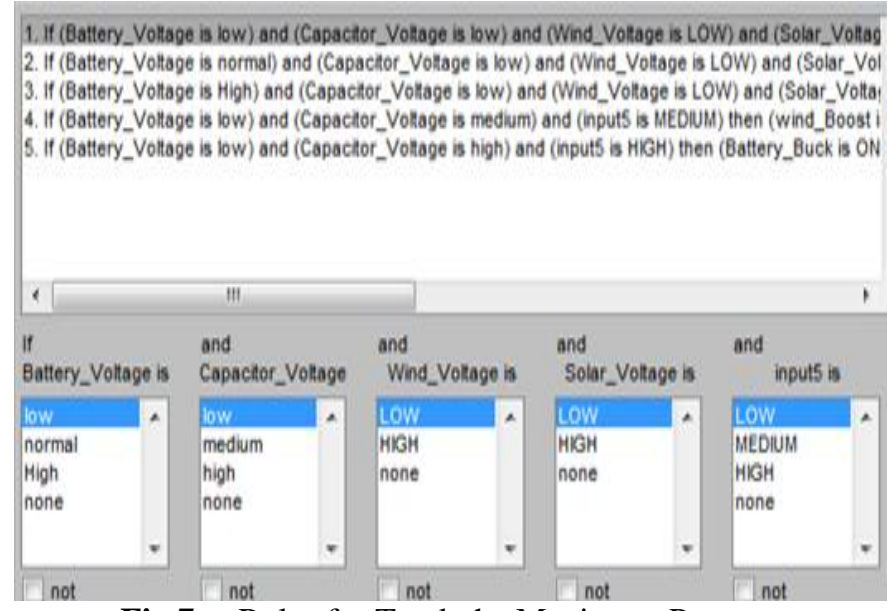

Fig.7.a. Rules for Track the Maximum Power

This fig.7(b)shows the rule based waveforms for maximum power tracking the solar and wind. it also shows the boost or buck operation for battery and capacitor charging or discharging output waveform.

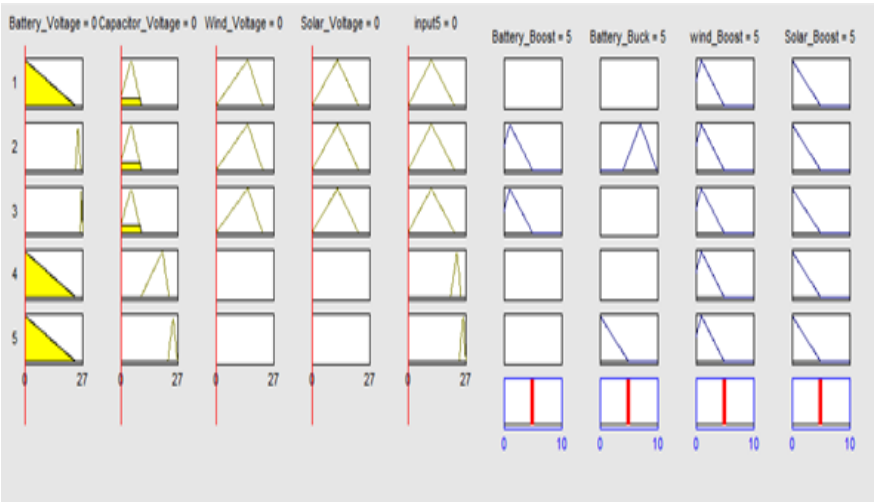

Fig.7.b. Rules waveform for the input voltages

\section{SIMULATION AND RESULT}

It consists of three ports. There are main port, battery port and load port. It is operates in three modes. Under running condition any one port supplying, one port is charging and another one is load port. The simulation parameters are input voltage is $12 \mathrm{~V}$ for PV and wind and the battery voltage is $24 \mathrm{~V}$. The load output power is $90 \mathrm{~W}$. 


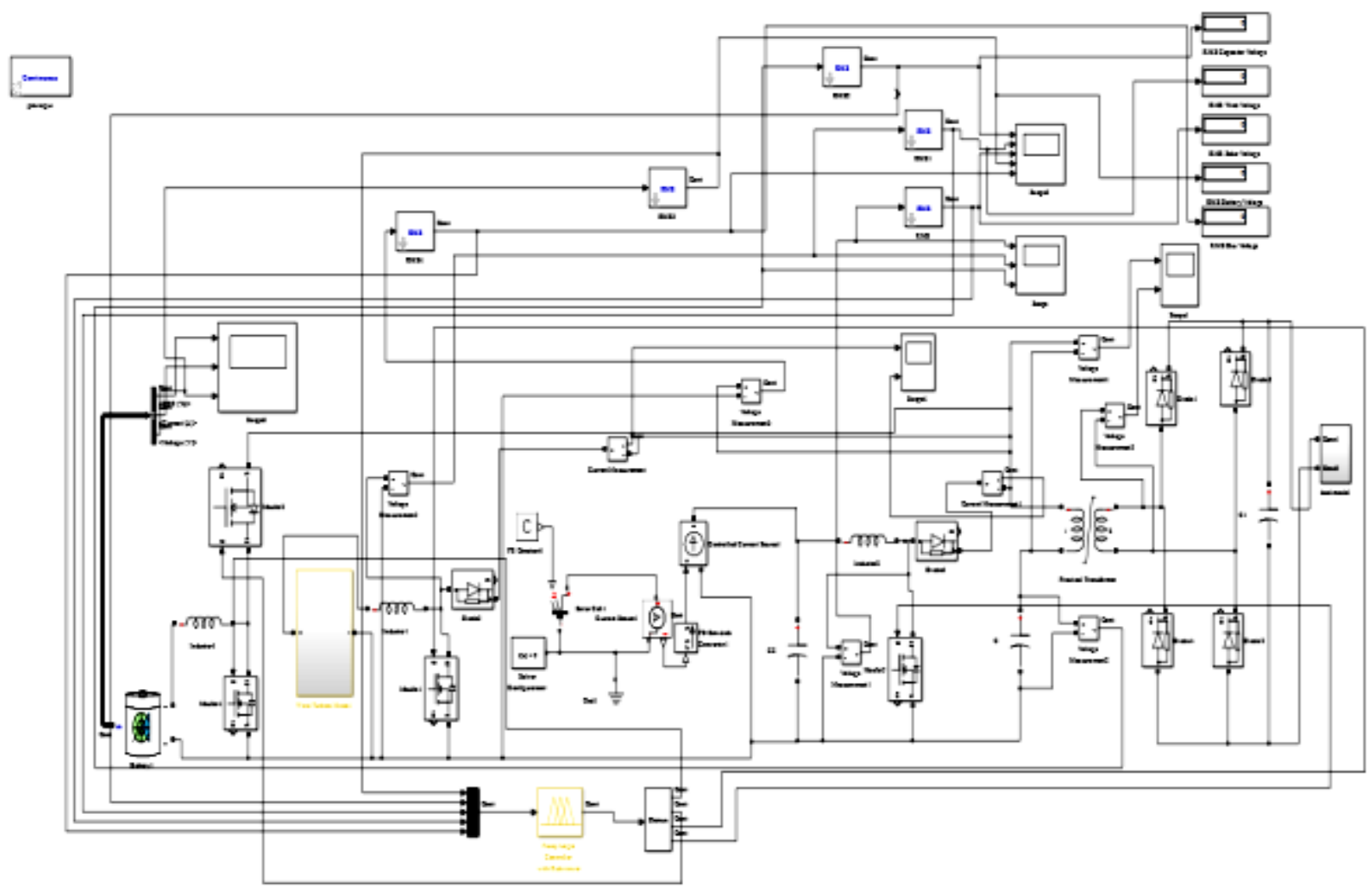

Fig.8. Converter Simulation

\subsection{Simulated Input Voltage}

The fig.9(a) corresponding voltage of the wind and solar is obtained. wind voltage is $12 \mathrm{v}$ and amplitude is $0.5 \mathrm{v}$. Firing pulse is generated by fuzzy control for MOSFET. Voltage across the capacitor is $1.05 \mathrm{v}$.

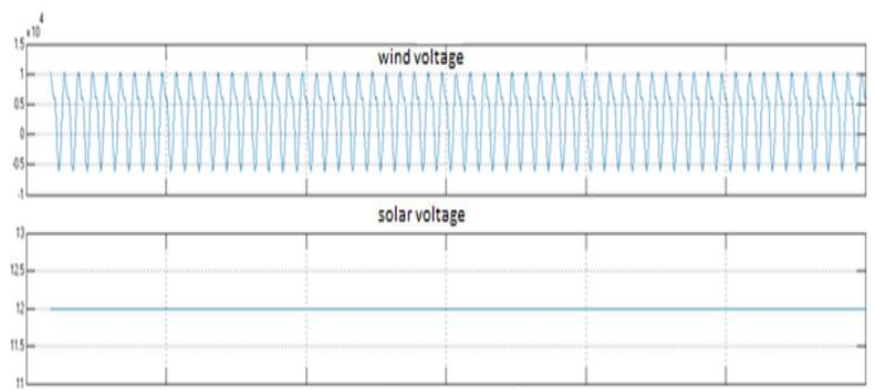

Fig.9.a.Input Voltage Waveform

\subsection{Voltage across the Capacitor}

The below fig.9(b) represents the measured voltage across the capacitor when charging and discharging condition. Capacitor charges voltage till equal to input voltage $12 \mathrm{~V}$ and increasing up to $15 \mathrm{~V}$. capacitor voltage will vary due to the reason of switch on and off condition.

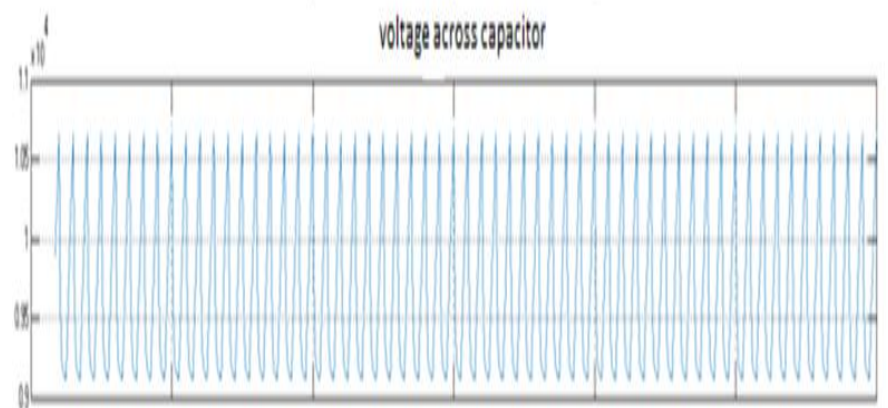

Fig.9.b Voltage across the Capacitor

\subsection{Mosfet Firing Pulses}

The below fig.9(c) represents the generating firing pulses to MOSFET. Using fuzzy control the firing pulses are generated by rule based system. It is used to trigger the MOSFET conducts. Fuzzy control pulse generator providing the high switching frequency, delay, width and $50 \%$ duty cycle.

firingoulse mostet

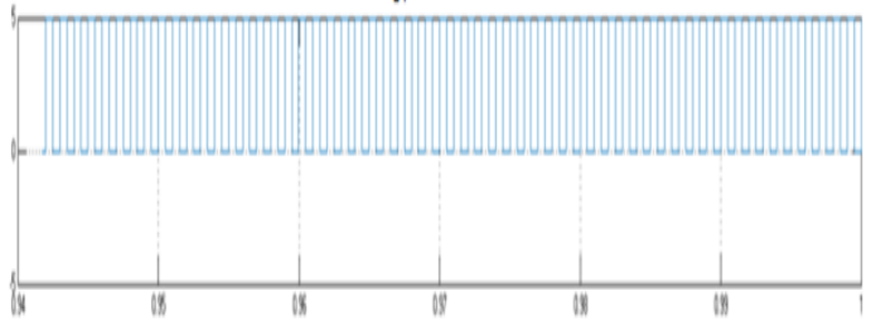

Fig.9.c firing pulses 


\subsection{Solar and Wind Current}

Multi port dc-dc converter for solar and wind current waveform. The simulated output current, which is measured across the output of motor loads by connecting a current measurement with scope.

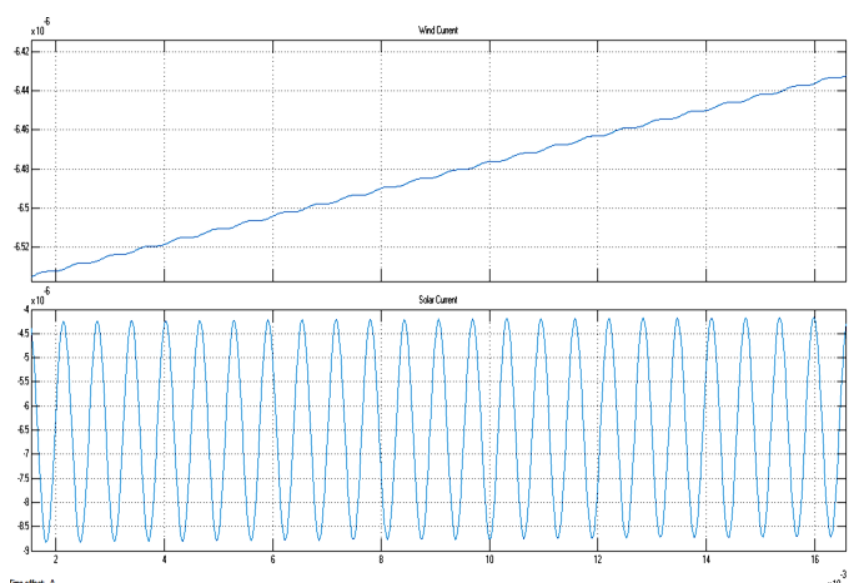

Fig.10. solar and wind current

\subsection{Solar and Wind Diode Current}

Simulation Diagram of multi port dc-dc converter for solar and wind diode current waveform. The simulated output current, which is measured across the output of motor loads by connecting a current measurement with scope.
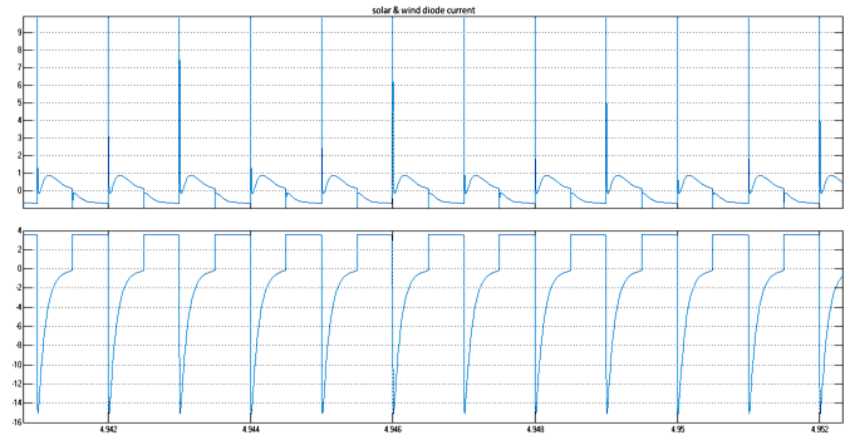

Fig.11. Diode Current

\subsection{Battery Input and Output Waveform}

Battery input and output waveform for the converter is simulated. The simulated input and output voltage, which is measured across the output of motor loads by connecting a voltage measurement with scope.

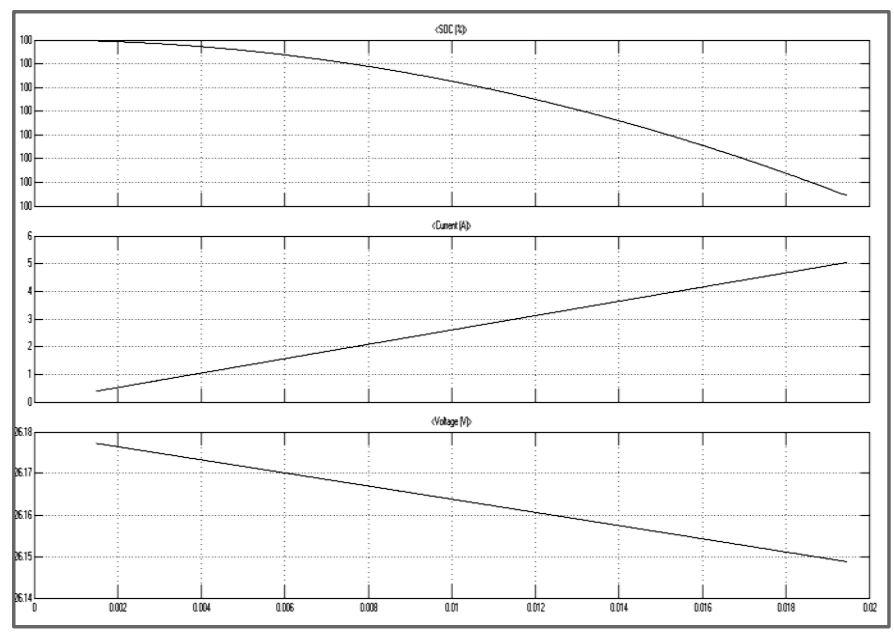

Fig.12. battery input and output

\subsection{Wind Turbine Generator Model}

This fig.13 shows the wind turbine generator, which is runs at low speed 10W, it converts to high speed use of gearbox. Alter the pitch angle to extract the maximum power at wind turbine and wind speed is depend upon the pitch angle.

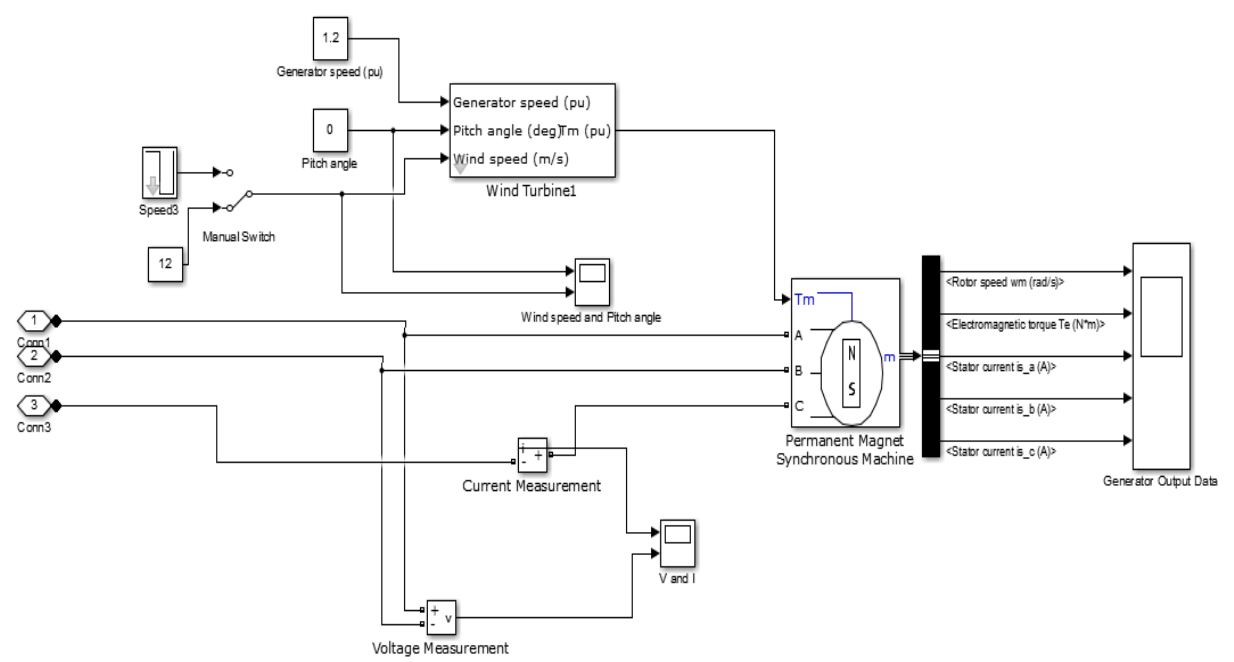

Fig.13.Simulation Diagram for Wind Turbine Generator 


\subsection{Dc Motor Model}

Simulation Diagram of multiport dc-dc converter load. This DC motor is placed as a load. With the help of scope the performance is analyzed through the wave form. Load voltage and current is obtained from dc motor load model.

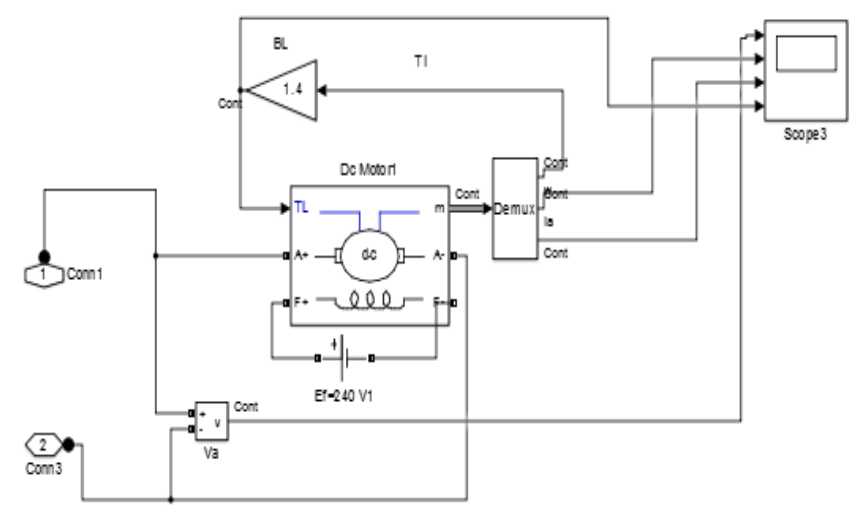

Fig.14. Simulation Diagram for DC motor

\subsection{Output Waveform of Load}

Multiport dc-dc converter load model of solar and wind. Three phase waveform is given clearly.

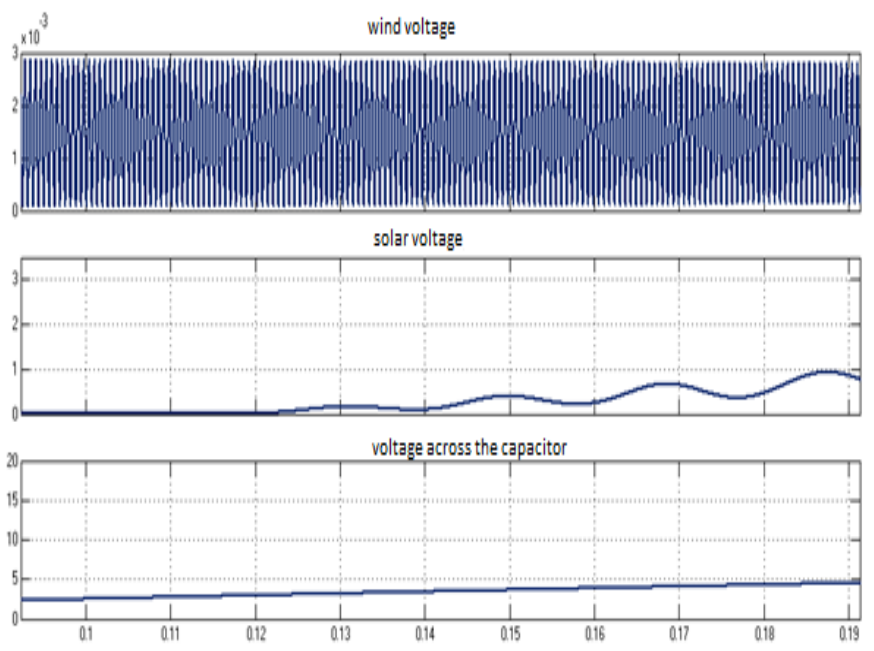

Fig.15. Load output

\subsection{Efficiency}

Three voltage sources were connected to the three input ports of the multiport converter to test its efficiency. During the test, the voltages of the three sources connected to the input ports solar and wind voltage were set to $12 \mathrm{~V}$ and the battery voltage is set as 24V.This fig.16(a) graph shows the input voltage and power related curve.

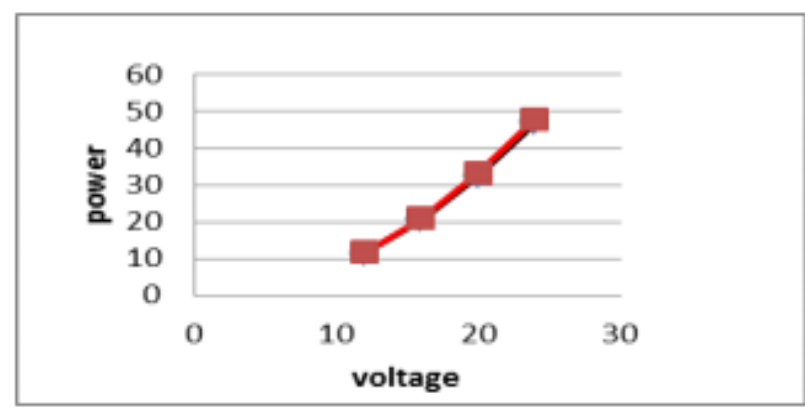

Fig.16.A.Input Voltage vs Power Curve

This fig.16(b) graph shows the measured efficiency with respect to the output of the converter. The efficiency increases with the increase of the output power. When the output power reaches $90 \mathrm{~W}$, the efficiency will reaches the $91.8 \%$. The efficiency gradually decreases with increase in load but always in above $90 \%$.

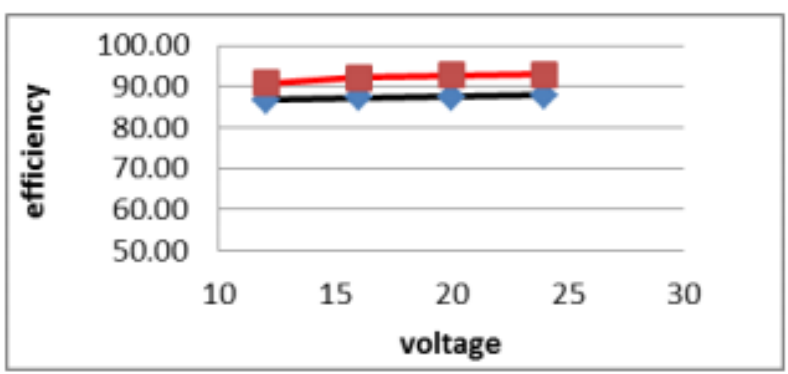

Fig.16.B Input Voltage vs Efficiency Curve

Table.2.Multiport dc-dc converter simulation parameters

\begin{tabular}{|l|l|}
\hline Parameters & Value \\
\hline Battery nominal voltage & $24 \mathrm{~V}$ \\
\hline Fully charged voltage & $26.1316 \mathrm{~V}$ \\
\hline MOSFET resistance & $1 \mathrm{ohm}$ \\
\hline Diode resistance & $0.1 \mathrm{ohm}$ \\
\hline Capacitor & $100 \mu \mathrm{f}$ \\
\hline Switching frequency & $5 \mathrm{KHZ}$ \\
\hline Carrier frequency & $1080 \mathrm{HZ}$ \\
\hline Motor current & $1 \mathrm{~A}$ \\
\hline Inductor & $.05 \mathrm{H}$ \\
\hline Motor resistance & $200 \mathrm{ohm}$ \\
\hline
\end{tabular}

\section{CONCLUSION}

This proposed multiport DC-DC converter consist of reduces the switches number, for the power management of various renewable energy source. Hybrid generation system and energy storage system are the source of the converter, simultaneous power management is applicable in this proposed topology. And soft switching operation is realized in the isolated high frequency transformer. The both buck and boost operation of the converter is depend on the switches. Simulation for multiport dc-dc converter is verified for either direction of power flow between two DC sources. 
In this system reverse direction of current flow and thereby the power, while maintaining the voltage polarity is not changed. Under different operating conditions including normal load, large load, small load, even load, the system can remain stable and controlled. The closed-loop control system for the proposed converter is highly stable.

\section{REFERENCES}

[1]. C. Zhao, S. Round, and J. Kolar, "An isolated three-port bidirectional DC- DC converter with decoupled power flow management," IEEE Trans.Power Electron., vol. 23, no. 5, pp. 2443-2453, Sep. 2008.

[2]. D. Liu and H. Li, "A ZVS bi-directional DC-DC converter for multiple energy storage elements," IEEE Trans. Power Electron., vol. 21, no. 5, pp. 1513-1517, Sep. 2006.

[3]. F. Forest, T. Meynard, E. Laboure, B. Gelis, J. Huselstein, and J. Brandelero, "An isolated multicell, intercell transformer converter for applications with a high step-up ratio," IEEE Trans. Power Electron., vol. 28, no. 3, pp. 1107-1119, Mar. 2013.

[4]. G. Su and F. Peng, "A low cost, triple-voltage bus DCDC converter for automotive applications," in Proc. IEEE Appl. Power Electron. Conf. Exposit., vol. 2. Mar. 2005, pp. 1015-1021.

[5]. H. Wu, R. Chen, J. Zhang, Y. Xing, H. Hu, and H. Ge, "A family of three-port half- bridge converters for a standalone renewable power system," IEEE Trans. Power Electron., vol. 26, no. 9, pp. 2697-2706, Sep. 2011.

[6]. J. Kassakian and T. Jahns, "Evolving and emerging applications of power electronics in systems," IEEE J. Emerging Sel. Topics Power Electron., vol. 1, no. 2, pp. 4758, Jun. 2013.

[7]. J. Zeng, W. Qiao, and L. Qu, "A single-switch isolated DC-DC converter for photovoltaic system," in Proc. IEEE Energy Convers. Congr. Exposit., Sep. 2012, pp. 3446-3452. [8]. O. Lucia, I. Cvetkovic, H. Sarnago, D. Boroyevich, P. Mattavelli, and F. C. Lee, "Design of home appliances for a DC-based nanogrid system: An induction range study case," IEEE J. Emerging Sel. Topics Power Electron., vol. 1, no. 4, pp. 315-326, Dec. 2013.

[9]. Y. Zhao, C. Wei, Z. Zhang, and W. Qiao, "A review on position/speed sensor less control for permanent-magnet synchronous machine-based wind energy conversion systems," IEEE J. Emerging Sel. Topics Power Electron., vol. 1, no. 4, pp. 203-216, Dec. 2013.

[10]. Z. Wang and H. Li, "An integrated three-port bidirectional DC-DC converter for PV application on a DC distribution system," IEEE Trans. Power Electron., vol. 28, no. 10 , pp. $4612-4624$, Oct. 2013. 